\title{
CONSUMO DE ALIMENTOS FONTES DE PROTEÍNA ANIMAL POR ESTUDANTES UNIVERSITÁRIOS EM RESTAURANTES COMERCIAIS AUTOSSERVIÇO
}

\author{
Juliana Kise TRINDADE ${ }^{1}$ \\ Mariana Granja de LIMA ${ }^{2}$ \\ Mônica Glória Neumann SPINELLI ${ }^{3}$ \\ Andrea Guerra MATIAS ${ }^{4}$
}

${ }^{1}$ Discente do curso de Nutrição, Centro de Ciências Biológicas e da Saúde, Universidade Presbiteriana Mackenzie. julikst@hotmail.com

${ }^{2}$ Discente do curso de Nutrição, Centro de Ciências Biológicas e da Saúde, Universidade Presbiteriana Mackenzie. nanaglima@ hotmail.com

${ }^{3}$ Nutricionista, mestre e doutora em Saúde Pública (concentração em nutrição) pela Universidade de São Paulo. Professora adjunta do curso de Nutrição, Centro de Ciências Biológicas e da Saúde, Universidade Presbiteriana Mackenzie.monicaspi404@gmail.com

${ }^{4}$ Nutricionista, mestre e doutora em Saúde Pública (concentração em nutrição) pela Universidade de São Paulo. Professora adjunta do curso de Nutrição, Centro de Ciências Biológicas e da Saúde, Universidade Presbiteriana Mackenzie. andrea.matias@mackenzie.br

Recebido em: 17/11/2015 - Aprovado em: 13/07/2016 - Disponibilizado em: 18/12/2016

\begin{abstract}
RESUMO
Devido ao aumento progressivo de refeições realizadas fora de casa, os restaurantes do tipo self-service têm sido umas das modalidades de atendimento em alimentação mais frequentada, inclusive, por estudantes universitários. Mesmo com tanta diversidade nos pratos brasileiros, a preferência por carne é consenso entre os jovens. Desta forma, o presente estudo teve como objetivo avaliar o consumo de alimentos fontes de proteína animal por estudantes universitários em restaurantes do tipo self-service. Foram aplicados questionários em um complexo comercial com um pátio de alimentação comum a quatro restaurantes. A amostra foi composta de 67niversitários, sendo a distribuição entre os gêneros equilibrada. $O$ peso médio das refeições realizadas pelo sexo masculino foi de $538 \mathrm{~g}$ (DP \pm 157 ) enquanto o do sexo feminino foi de $389 \mathrm{~g}(\mathrm{DP} \pm 110)$. Quanto à quantidade de proteína recomendada no almoço $(30 \mathrm{~g})$, ambos os sexos ultrapassaram os valores, com destaque para os homens com média de $80 \mathrm{~g}(\mathrm{DP} \pm 57)$. Dentre os alimentos fontes de proteína animal mais escolhidos, destacaram-se a carne de boi (38\%) seguida de frango (32\%). Conclui-se um consumo elevado de alimentos fontes de proteína animal por estudantes universitários, de maneira que maiores esforços na educação nutricional desta população se fazem necessários.
\end{abstract}

Palavras-chave: proteína, peso, universitários, carne.

\section{FOOD CONSUMPTION OF ANIMAL PROTEIN SOURCES FOR COLLEGE STUDENTS IN RESTAURANTS OF SELF-SERVICE TYPE}

\begin{abstract}
Due to the gradual increase of meals made outside home, self-service restaurants have been one of the most popular option for college students. Even with the diversity of Brazilian food preparation, the preference for meat is a consensus among young people. Thus, this study aimed to evaluate animal protein food intake for college students in self-service restaurants. Questionnaires were used in a commercial complex with a common power courtyard to four restaurants. The sample consisted of 70 students, and the distribution between genders balanced. The average weight of the meals made by males was $538,46 \mathrm{~g}(\mathrm{SD} \pm 157$ ) while the female was $389,27 \mathrm{~g}$ ( $\mathrm{SD} \pm 110)$. Both sexes exceeded the recommended protein values $(30 \mathrm{~g})$, especially men with average of $79,6 \mathrm{~g}(\mathrm{SD} \pm 57)$. Among the food animal protein
\end{abstract}


sources chosen, the highlights were the beef (38\%) and chicken (32\%). It was concluded that college students have a high intake of animal protein, and a big effort in nutrition education will be needed for this population.

Keywords: Protein, weight, university, meat.

\section{INTRODUÇÃO}

A comensalidade contemporânea apresenta, entre outras características, a necessidade de adaptação do indivíduo ao meio urbano, ajustando-se às novas práticas alimentares, às questões temporais, espaciais e financeiras. Desta forma, têm-se registrado nos últimos anos, um aumento progressivo de refeições realizadas fora de casa do qual diversos autores relatam ser um quadro resultante do mundo globalizado, caracterizado pela falta de tempo para preparo e consumo dos alimentos (SANTOS et al., 2011; LEAL, 2010; JOMORI et al., 2008).

Uma das modalidades de atendimento em alimentação fora de casa, que tem sido muito utilizada pelos brasileiros atualmente é o restaurante por peso. Esse constitui-se num modelo self-service ou autosserviço, onde o comensal escolhe o que deseja consumir pagando o equivalente ao peso das preparações culinárias que colocou em seu prato. Considerando-se que, nos restaurantes por peso, a oferta de preparações culinárias é ampla, destaca-se a importância das escolhas feitas pelos clientes, que pode não ser necessariamente saudável (SPINELLI et al., 2015; JOMORI et al., 2008; JOMORI, 2006).

Estudantes universitários utilizam esses estabelecimentos permitem, de maneira rápida e com um custo semelhante ao de um lanche, que o consumidor realize uma refeição completa. Para muitos, o ingresso na faculdade corresponde ao primeiro momento em que terão de se responsabilizar por sua moradia, alimentação e gestão de suas finanças. A inabilidade para realizar tais tarefas, juntamente com fatores psicossociais, estilo de vida e situações próprias do meio acadêmico, podem resultar em omissão de refeições, consumo de lanches rápidos e ingestão de refeições nutricionalmente desequilibradas. Pesquisas avaliando os hábitos alimentares desta população relatam, de forma geral, uma baixa prevalência de alimentação saudável, com elevada ingestão de alimentos doces e gordurosos e baixa ingestão de frutas e hortaliças. Os maus hábitos alimentares desses universitários poderiam estar sendo influenciados pelos novos comportamentos e relações sociais, sugerindo indícios de compulsão alimentar em alguns alunos que, ansiosos, podem transformar a alimentação em "válvula de escape" para as situações de estresse físico e mental (DUARTE et al., 2013; PETRIBÚ et al., 2009; MARONDELLI et al., 2008; PROENÇA et al., 2005; VIEIRA et al., 2002). frequentemente esse tipo de serviço, pois 
Embora o hábito alimentar da população brasileira envolva diferentes pratos regionais oriundos de diferenças étnicas e culturais, pode ser considerado bastante homogêneo. Pesquisa realizada em dez cidades brasileiras com mais de um milhão de habitantes e em cinco segmentos diferentes de renda, com pessoas entre 17 e 65 anos, apontou que $94 \%$ das pessoas consomem arroz e feijão, acompanhados por algum tipo de carne vermelha (69\%) ou de galinha (42\%), saladas (30\%), macarrão (24\%), verduras em geral (22\%) e legumes (18\%), mostrando que apesar da grande variedade alimentos, a escolha por alimentos ricos em proteínas, como a carne, é característica de toda a população. Esse estudo mostra, ainda, que o consumo de carne sem qualquer especificação, não apresenta grandes variações entre nenhum dos segmentos sociais. Em relação ao consumo dos variados tipos de carne, a maior variação ocorre na faixa etária entre 17 e 19 anos, dos quais $89,5 \%$ dos pesquisados declaram consumir carne vermelha (BARBOSA, 2007).

Estudos de Santos et al (2014) e Garcia (2013) verificaram que os universitários consomem mais carne bovina do que peixes e frutos do mar.

Conforme o Guia Alimentar para a População Brasileira (2014), as carnes vermelhas são excelentes fontes de proteína de alta qualidade. Contêm cerca de 20 a $40 \%$ de proteínas de alto valor biológico, com boas fontes de aminoácidos essenciais. Apresentam teor elevado de muitos micronutrientes, especialmente ferro de alta biodisponibilidade, zinco, selênio, vitaminas como B6 e B12, porém tendem a ser ricas em gorduras e, em especial, as saturadas, que, quando consumidas em excesso, aumentam o risco de doenças cardiovasculares e outras doenças crônicas.

Provavelmente seus altos teores de ferro, as gorduras saturadas, o colesterol e a formação, durante a cocção, de substâncias potencialmente carcinogênicas sejam responsáveis pelas evidências convincentes entre o consumo excessivo de carnes vermelhas e processadas com doenças cardiovasculares, diabetes (MICHA et al., 2010) e podem aumentar o risco de câncer de intestino (BRASIL, 2014; HU et al., 2011; WCRF, 2007; MAHAM, 2010).

Existe um aumento de consumo de frango no Brasil facilitado pela sua acessibilidade em relação ao preço. Apesar disso, a preferência ainda recai sobre a carne bovina, que popularmente tem o crédito de proporcionar mais saciedade do que a carne branca (SANTOS,2008).

O consumo excessivo de proteína tem sido estudado há muitos anos, contudo ainda há controvérsias entre os autores quanto aos possíveis impactos danosos que este consumo pode causar à saúde. Algumas explicações para a possível relação entre alta ingestão de proteína e dano renal são de que, como os rins 
eliminam os produtos do metabolismo da proteína (como ureia, amônia, dentre outros resíduos nitrogenados), seu consumo elevado pode aumentar a taxa de filtração glomerular, causando aumento da pressão dentro dos glomérulos e fazendo com que a função renal seja prejudicada progressivamente. Além disso, pode haver sobrecarga do fígado, por ser o órgão responsável pela metabolização de aminoácidos. Outro problema discutido relacionado ao excesso da ingestão de proteínas é a possível contribuição para o desenvolvimento da aterosclerose e doenças cardíacas quando uma vez que o excesso de proteína na circulação sanguínea, depois de degradado, é armazenado na forma de gordura. Outro agravante do consumo em excesso de proteína é o aumento da excreção de cálcio e, portanto, a diminuição da utilização desse mineral (SAVIO et al., 2005; MARTIN et al., 2005; KNIGHT et al., 2003).

Sabendo, portanto, da inadequação alimentar de universitários, aliado ao maior consumo de proteínas por parte dos brasileiros, este estudo visa analisar quantitativamente o consumo de alimentos fontes de proteína animal por estudantes universitários em restaurantes comerciais autosserviço, na região central do município de São Paulo.

\section{METODOLOGIA}

Estudo transversal realizado no primeiro semestre do ano de 2015. Foram aplicados questionários com questões fechadas em 67 estudantes universitários (33 homens e 34 mulheres) em um complexo comercial na região central da cidade de São Paulo/SP, com um pátio de alimentação comum a quatro restaurantes comerciais autosserviço. Da amostra inicial de 70 pessoas foram excluídos 3 por inconsistência de dados.

Os critérios de inclusão na amostra foram: ser estudante universitário, ter escolhido algum dos restaurantes de autosserviço do pátio de alimentação para realizar a refeição, e conter alimentos fontes de proteína animal no prato.

Foi desenvolvido um questionário que levantou dados de sexo, idade e hábito alimentar relacionado ao consumo de alimentos fontes de proteína de origem animal (carne bovina, suína, ave, pescado, miúdos, ovo e/ou laticínios). Também foram registrados o peso da refeição e as respectivas fontes de proteína de origem animal observadas no prato.

Nos casos em que os entrevistados não recordavam o peso do prato, foi solicitado o nome do restaurante e o valor da refeição e, desse modo, a partir do preço do quilo foi realizado o cálculo do peso da refeição correspondente.

As porções de alimentos fontes de proteína animal das preparações salgadas de cada indivíduo foram coletadas em medidas caseiras e convertidas para o valor em peso 
com o auxílio de tabela de equivalência (PINHEIRO, 2004). Posteriormente, foram realizados os cálculos da quantidade de proteína nos alimentos e na refeição por meio de Tabela de Composição dos Alimentos (UNICAMP, 2006).

Para o almoço considerou-se o Valor Energético Total (VET) de 30 a 40\% do valor diário - 600 a 800kcal (ABREU et al, 2013; GUIMARÃES; GALIZA, 2008), e para proteína considerou-se como adequado $\mathrm{O}$ valor mínimo de $10 \%$ das $600 \mathrm{kcal}(15 \mathrm{~g})$ e o valor máximo de $15 \%$ de $800 \mathrm{kcal}(30 \mathrm{~g})$ (WHO 2001), desse modo, considerou-se como adequada a variação de 15 a $30 \mathrm{~g}$ de proteína no almoço, para uma dieta de 2000 kcal.

Todas as informações foram tabuladas no programa Microsoft Excel 2013 e os resultados apresentados na forma de estatísticas descritivas.

Este trabalho atende as considerações éticas de pesquisa com seres humanos segundo a resolução $\mathrm{n}^{\circ} 466 / 12$, tendo sido aprovado pelo CONEP $n^{\circ}$ 48483015.7.0000.0084.

\section{RESULTADOS E DISCUSSÃO}

Os participantes apresentaram média de 19 anos com amplitude de 17 a 28 anos. A distribuição entre os gêneros foi equilibrada, sendo $50,7 \%$ do sexo masculino.
Dentre os alimentos fontes de proteína animal mais escolhidos, destacaram-se a carne de boi e frango como demonstra o Gráfico 1.

Gráfico 1. Tipos de alimentos fontes de proteína animal mais consumidos no almoço. São Paulo, 2015.

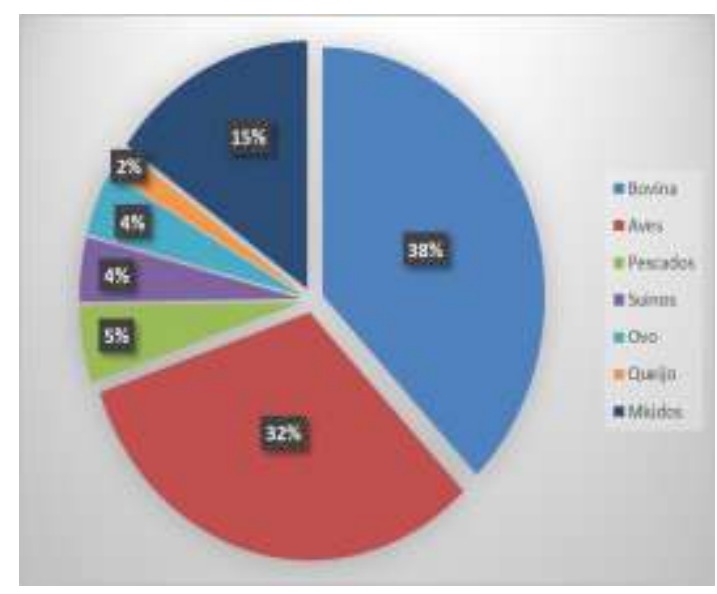

O resultado apresentado no Gráfico 1 corrobora os resultados da POF (Pesquisas de Orçamentos Familiares) 2002-2003 e 20082009 que mostram que a carne bovina ainda é a carne mais consumida pelas famílias brasileiras, com uma aquisição domiciliar per capita anual de $22 \mathrm{~kg}$. Em segundo lugar aparece a carne de frango, com uma aquisição per capita de 9,8 kg e em terceiro a carne suína com 4,6 kg. Segundo, ainda, dados da POF 2008/2009 o consumo de carne bovina é de 63,2 g/dia e de aves 32,5 g/dia.

Observou-se representativo consumo de produtos classificados como miúdos ou vísceras, ficando em terceiro lugar na preferência. No entanto, esta frequência foi devida ao consumo de coração de frango, única opção dessa categoria de alimentos. 
Embora nos países ocidentais, os miúdos tenham caído em desuso, possivelmente pelas restrições alimentares de grande parte da população antes acostumada a usá-los em sua dieta, atualmente isso está se revertendo a partir da ideia de se tirar proveito absoluto dos animais e por apresentam um excelente custo/benefício, tanto no preparo por quilo, como também por seu alto valor nutricional (MARTIN, 2005).

Costa et al. (2010) e Levy-Costa (2005) observaram que o consumo diário de carne vermelha está diretamente associado ao nível socioeconômico. Esses estudos apontaram que estatisticamente os adolescentes de maior nível socioeconômico apresentam maior ingestão de carnes vermelhas, sendo a renda um fator importante na determinação do consumo alimentar da população. Apesar de não ter sido questionado o nível socioeconômico dos universitários pesquisados, infere-se que possam apresentar um padrão de moderado a alto, visto que estudam em uma universidade privada vizinha aos estabelecimentos onde se coletaram os dados e fazem uso de restaurantes comerciais.

O peso médio das refeições foi de 464g (DP \pm 154). Segundo Santos et al. (2011) a quantidade de refeições consumida em restaurantes por peso é menor do que em domicílio, visto que o preço a ser pago pela refeição é determinado pela quantidade consumida. Em uma pesquisa também realizada em restaurantes comerciais por quilo, Abreu e Torres (2003) encontraram uma média de peso de $454 \mathrm{~g}$.

Analisando individualmente os dados de cada sexo, observa-se, no presente estudo, resultados semelhantes à literatura, na qual os homens consomem maior quantidade de alimentos do que as mulheres. $\mathrm{O}$ peso médio para o sexo masculino foi de $538 \mathrm{~g}(\mathrm{DP} \pm 157)$ enquanto o sexo feminino foi de $389 \mathrm{~g}$ (DP \pm 110). Um estudo, que analisou os dados coletados pela Pesquisa de Orçamento Familiar (POF) de 2008-2009, indicou uma associação entre alimentação fora de casa com excesso de peso entre os homens, mas não em mulheres, devido a estas apresentarem uma maior preocupação com a saúde e estética, fazendo, assim, escolhas alimentares mais saudáveis tanto em qualidade quanto em quantidade (BERNARDO, 2010).

Gráfico 2. Comparação do consumo médio em gramas de proteína no almoço por universitários segundo sexo e recomendação. São Paulo, 2015.

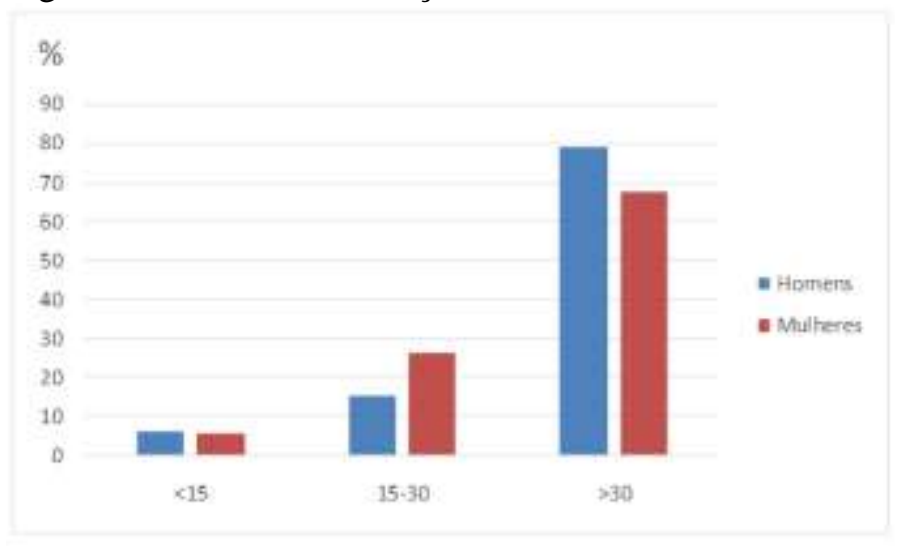

Constatou-se, também, que a maioria dos estudantes $(91,74 \%) \quad$ consumiam 
alimentos de fontes proteicas de origem animal em outras refeições além da avaliada, e a média de refeições diárias foi de 4 . Por meio do Guia Alimentar para a População Brasileira, o Ministério da Saúde recomenda a realização de pelo menos 5 refeições ao dia, sendo as principais o café da manhã, almoço e jantar, e lanches intercalando estas grandes refeições (BRASIL, 2014). Dentro deste contexto, se os indivíduos cujo consumo de alimentos fonte de proteína foi elevado seguirem este padrão nas demais refeições, possivelmente apresentarão um cômputo diário de proteína acima de níveis adequados.

Considerando o valor máximo recomendado de proteína em relação ao VET (15\%) e o percentual máximo do VET para o almoço (40\%-800 kcal), tem-se como referência o valor máximo de $30 \mathrm{~g}$ de proteína para esta refeição. Como pode ser observado no gráfico 2, ambos os sexos apresentaram consumo em excesso. Observou-se para as mulheres o consumo médio de 40,2g (DP= $17,8 \mathrm{~g})$, e para os homens $79,7 \mathrm{~g}(\mathrm{DP}=56,7 \mathrm{~g})$ excedendo $34 \%$ e $166 \%$, respectivamente. Kazapi et al. (2001) sugerem que o alto consumo de proteínas por estudantes do sexo masculino pode ser explicado pela crença da relação entre este e o aumento da massa muscular.
Gráfico 3. Distribuição percentual de universitários quanto ao consumo de proteína no almoço autosserviço. São Paulo, 2015.

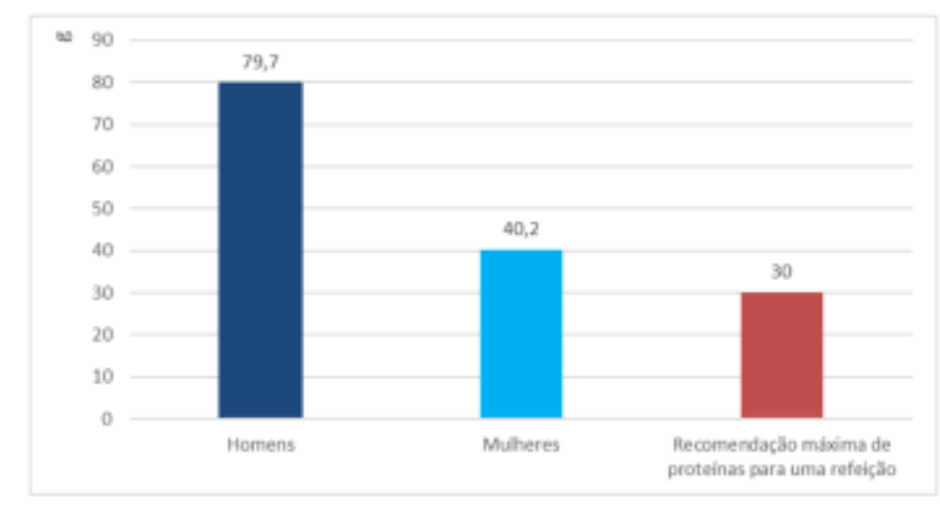

A quantidade de proteína animal consumida foi classificada em: menor de $15 \mathrm{~g}$, entre 15 e $30 \mathrm{~g}$, superior a $30 \mathrm{~g}$. O intervalo de consumo proteico de 15 e 30 g foi considerado adequado (WHO 2001), embora tenha sido observado neste estudo apenas o consumo de proteína de origem animal das preparações salgadas, subestimando o consumo total de proteína. Apresentaram consumo superior a $30 \mathrm{~g} 78,8 \%$ dos homens e $67,7 \%$ das mulheres.

Observou-se que 51,4\% apresentaram consumo superior a $75 \mathrm{~g}$, valor de referência diária para o consumo de proteína, somente com as preparações proteicas salgadas na refeição almoço. Deste total 48,5 eram homens, destaque que um indivíduo apresentou consumo superior a $250 \mathrm{~g}$.

Estas observações corroboram o estudo de Feitosa et al. (2010) que refere menor consumo de carnes entre mulheres. Um estudo realizado por Spinelli et al. (2015), que também avaliou a quantidade de proteína no 
almoço, relata uma variação da quantidade de proteína consumida entre 37,5 e 111,2g enquanto a recomendação máxima para uma refeição é de $30 \mathrm{~g}$.

É importante destacar que esse consumo proteico advém principalmente das carnes, o que sugere que possa haver um excesso de gordura saturada, uma vez que muitas delas são carnes gordas como picanha, alcatra, embutidos (linguiça), coração de frango, apresentadas nos buffets sob a forma de churrasco.

Segundo diversos autores, como Maham e Escott-Stump (2010), Martin et al. (2005), Knight et al. (2003), a ingestão excessiva de proteína pode ser prejudicial, pois pode afetar o metabolismo hepático e renal, já que muitos subprodutos do metabolismo proteico e nitrogenado têm sua síntese e excreção nesses órgãos.

Existem várias razões para sugerir que as dietas hiperproteicas possam induzir mudanças significativas na função renal $\mathrm{e}$ outros aspectos do metabolismo causando hiperfiltração glomerular e hiperemia, proteinúria e aumento dos fatores de risco para a produção de urolitíase e diminuição do $\mathrm{pH}$ da urina. Outro efeito colateral que poderia estar associado à maior ingestão proteica, por indivíduos saudáveis, seria a maior excreção urinária de cálcio (EISENSTEIN, 2002).

Portanto, o consumo de dietas ricas em proteína, superiores aos padrões estabelecidos, podem causar consequências metabólicas em vários sistemas e órgãos (MARTIN et al., 2005; KNIGHT et al., 2003; FRIEDMAN, 2000).

\section{CONCLUSÃO}

Pode-se concluir que há um consumo elevado de alimentos fontes de proteína animal por estudantes universitários, principalmente pelo sexo masculino. Há uma maior preferência por carne bovinas e aves. Miúdos que ficaram relegados por vários anos ao segundo plano, por serem consideradas carnes menos nobres, aparecem como terceira opção de escolha. Diante destes dados, faz-se necessário maiores esforços na educação nutricional desta população, inclusive, quanto aos possíveis danos à saúde que o excesso de proteínas possa acarretar.

\section{REFERÊNCIAS}

ABREU, E. S.; TORRES, E. A. F. S. Restaurante "por quilo": vale o quanto pesa? Uma avaliação do padrão alimentar em restaurantes de São Paulo, SP. Nutrire, v.25, p.7-22, 2003.

ASSIS, M. A. A. Consulta de Nutrição: Controle e prevenção de colesterol elevado. Florianópolis: Insulan, 168p. 1997.

BARBOSA, L. Feijão com arroz e arroz com feijão: o Brasil no prato dos brasileiros.

Horiz. Antropol.,v.13,n.28,p.87-116.

BERNARDO, G. L. "Diversidade alimentar saudável dos pratos de comensais que almoçam em restaurante por peso". Dissertação de Mestrado em Nutrição, no 
Programa de Pós-Graduação em Nutrição. Florianópolis, UFSC, 2010.

BRASIL, MINISTÉRIO DA SAÚDE: Guia Alimentar para População Brasileira promovendo a alimentação saudável. Normas e manuais técnicos: Brasília, 2014.

BRASIL. Instituto Brasileiro de Geografia e Estatística. Pesquisa de Orçamentos Familiares 2008-2009: despesas, rendimentos e condições de vida. Rio de Janeiro: IBGE; 2010.

COSTA, M. G. et al. Consumo de carne vermelha entre adolescentes do sul do Brasil. XIX CIC, XII EMPOS, 2010.

EISENSTEIN, J.; ROBERTS, S.B.; DALLAL, G.; SALTZMAN, E. High-protein weight-loss diets: are they safe and do they work? A review of the experimental and epidemiologic data. Nutr Rev.,v. 60,n.7, p.189-200,2002.

FEITOSA et al. Hábitos alimentares de estudantes de uma universidade pública no Nordeste, Brasil. Alim Nutr, Araraquara, v. 21, n. 2, p. 225-230, 2010.

FRIEDMAN AN. High-protein diets: Potential effects on the kidney in renal health and disease. Am J Kidney Dis, v. 44,p. 950962,2000 .

GARCIA, D. et al. Physical Activity and Dietary Habits in a University Population. Biomed Biopharm Res. Portugal, v. 9, n. 2, p. 147-158, 2013.

GUIMARÃES A.; GALISA M. S. Cálculos nutricionais: conceitos e aplicações práticas. São Paulo: M. Books, 91p. 2008.

HU, J: LA VECCHIA, C.; MORRISON, H; et al. Salt, processed meat and the risk of câncer. Eur J Cancer Prev. n.20,p.132 - 139, 2011.

JOMORI, M. M. Escolha alimentar do comensal de um restaurante por peso.
Dissertação de mestrado em Nutrição, no Programa de Pós-Graduação em Nutrição. Florianópolis, UFSC, 2006.

JOMORI, M. M.; PROENÇA, R. P. C.; CALVO, M. C. Escolha alimentar: a questão de gênero no contexto da alimentação fora de casa. Caderno Espaço Feminino, v.19, n.1, p. 369-384, 2008.

KAZAPI, I.M.; DI PIETRO, P.F.; AVANCINI, S.R.P.; FREITAS; S.T.F.; TRAMONTE, V.L.C.G. Consumo de energia e macronutrientes por adolescentes de escolas públicas e privadas. Rev Nutr. v.14,p. 27-33, 2001.Suplemento.

KNIGHT, E.L.; STAMPFER, M.J.; HANKINSON, S.E.; SPIEGELMAN, D.; CURHAN, G.C. The impact of protein intake on renal function decline in women with normal renal function or mild renal insufficiency. Ann Intern Med.v.138, n.6,p.460-7, 2003.

LEAL, D. Crescimento da alimentação fora do domicílio. Segurança Alimentar e Nutricional, v. 17,n.1,p. 123-132, 2010.

LEVY-COSTA, Renata Bertazzi et al . Disponibilidade domiciliar de alimentos no Brasil: distribuição e evolução (1974-2003). Rev. Saúde Pública, São Paulo, v. 39, n. 4, p. 530-540

MAHAM, L. K.; ESCOTT-STUMP, S. Krause: Alimentos, nutrição e dietoterapia. $12^{\mathrm{a}}$ edição. Rio de Janeiro: Elsevier, 2010.

MARTIN, W.F.; ARMSTRONG, L.E.; RODRIGUEZ, N.R. Dietary protein intake and renal function. Nutr Metab (Lond). 2005 .

MARTIN, P. Miúdos. Nutrição em Pauta, ano XIII,n.70, 2005

MICHA,R.;WALLACE,S.K.;MOZAFFARIA N,D. Red and processed meat consumption and risk of incident coronary heat disease, 
stroke, and diabetes mellitus: a systematic review and meta-analysis. Circulation, n.121,p.2271-2283, 2010.

NEPA - NÚCLEO DE ESTUDOS E PESQUISAS EM ALIMENTAÇÃO. Tabela Brasileira de Composição de Alimentos (TACO). $1^{\text {a }}$ ed. Campinas: NEPA UNICAMP, 2004. 42 p.

PINHEIRO, A. B. V. Tabela para avaliação de consumo alimentar em medidas caseiras. 5. ed. São Paulo: Atheneu, 131 p. 2004.

PROENÇA, R.P.C.; SOUZA, A.A.; VEIROS, M.B.; HERING, B. Qualidade nutricional e sensorial na produção de refeições.

Florianópolis (SC): Editora da UFSC; 2005.

SANTOS,A.K.G.V.dos;

REIS,C.C.;CHAUD,D.M.A.;MORIMOTO,J.

M. Qualidade de vida e alimentação de estudantes universitários que moram na região central de São Paulo sem a presença dos pais ou responsáveis. Simbio-

Logias,v.7,n.10,p.76-94,2014.

SANTOS,L.A.S. O corpo, o comer e a comida. Salvador:EDUFBA, 208.

SANTOS, M. V. PROENÇA, R. P. C.; FIATES, G. M. R.; CALVO,M.C.M . Os Restaurantes por peso no contexto de alimentação saudável fora de casa. Rev. Nutr.,v. 24, n. 4, p.641-649, 2011.

SAVIO, KEO.; COSTA, T.H.M.; MIAZAKI, E.; SCHMITZ, B.A.S. Avaliação do almoço servido a participantes do programa de alimentação do trabalhador. Saúde Públ. 39(2): 148-55, 2005.

SCHLINDWEIN, M.M.; KASSOUF, A.L. Análise da influência de alguns fatores socioeconômicos e demográficos no consumo domiciliar de carnes no Brasil. Revista de Economia e Sociologia Rural, v.44, n.3, p.549-572, 2006.

SPINELLI, M. G. N; VILAS, S. R. e MELO, V. Selección Proteínica y cantidad de sodio en comidas de uma unidad de alimentación. Anais do XII Congreso Argentino de Graduados de Nutrición. 2015.

UNICAMP - UNIVERSIDADE ESTADUAL DE CAMPINAS. Núcleo de Estudos e Pesquisas em Alimentação. Tabela brasileira de composição de alimentos. Taco, versão 2.2.ed.Campinas:Ed. Unicamp,2006.112p.

VIEIRA, V. C. R.; PRIORE, S.E.; RIBEIRO; S.M.R.; FRANCESCHINI, S.C.C.;

ALMEIDA, L.P. Perfil socioeconômico, nutricional e de saúde de adolescentes recémingressos em uma universidade pública brasileira. Rev Nutr. , 15:273-82. 2002.

WCRF - WORLD CANCER RESEARCH FUND / AMERICAN INSTITUTE FOR CANCR RESEARCH. Food, nutrition, physical activity and the prevention of cancer: a global perspective. Washington DC:AICR, 2007.

WORLD HEALTH ORGANIZATION. Diet, nutrition and the prevention of chronic diseases. WHO - Technical Report Series 797). Geneva: WHO; 2001. 